\title{
Study on Watershed Ecological Compensation Mechanism Based on Evolutionary Game Theory
}

\author{
Yunpeng $\mathrm{Hu}^{1,}$, , Shubo Jiang ${ }^{2,}$ b* $^{*}$ \\ ${ }^{1}$ Department of Economics, Harbin University of Commerce, Harbin, Heilongjiang, China \\ ${ }^{2}$ Department of Economics, Harbin University of Commerce, Harbin, Heilongjiang, China \\ a18637825907@163.com \\ b* jiangshubo333@126.com
}

\begin{abstract}
Watershed ecological compensation is an effective way to protect the ecological environment. By balancing the interests, the cost and benefit of the protector and the destroier of the ecological environment can be reasonably matched, so as to realize the sustainable development of the economy and society and the sustainable utilization of resources. However, there are obvious contradictions and conflicts between the economic goals and the resource goals of the upstream and downstream governments, which make the stakeholders of ecological compensation in the basin have the typical characteristics of game. In this paper, based on the evolutionary game theory, the cross-basin ecological compensation mechanism was studied, and the difficulties and obstacles encountered in the process of watershed ecological compensation were discussed.
\end{abstract}

\section{Keywords: Ecological compensation, Evolutionary Game Theory, Dilemma of the Prisoner}

\section{INTRODUCTION}

The rapid development of China's society and economy and the rapid advancement of urbanization have caused great pressure to the regional environment, resulting in the imbalance of social, economic and environmental development, and increasing pressure on the ecological environment. As a kind of public goods, watershed environment is not competitive in use and exclusive in income. Water environmental pollution (the tragedy of the Commons) is essentially the irrational behavior of the collective caused by the aggregation of individual rationality, that is, everyone wants to maximize their own interests and imposes externalities on others, which causes the expansion of social costs and leads to "tragedy" [1].The water quality in the upper reaches has a direct influence on the water environment in the lower reaches due to the transboundary mobility of water resources in the basin. When the upstream region pursues the rapid economic development at the expense of the environment, negative externalities will be generated, and the pollution cost in the basin will be transferred to the downstream region, which will lead to the dissatisfaction of the downstream region. On the contrary, when the upstream region actively improves the water environmental quality, the downstream region does not pay the treatment cost and enjoys the positive externality spillover effect, resulting in the "free ride" phenomenon. As an effective means of economic incentive, the basin ecological compensation mechanism harmonizes the interest relations between the upstream and downstream regions by internalizing the externalities and paying a certain fee to the providers of ecological services, thus realizing the "Pareto Optimality" in the economic sense .

Ecological compensation is an effective method of ecological environment protection based on the coordination of economic development and environmental protection concept, through the balance of interest prompted the protector of the ecological environment and vandals in the costs and benefits of matching more reasonable, realize the internalization of externality, then realize the sustainable development of economic and social and sustainable utilization of resources [2].As far as compensation means are concerned, it mainly includes two kinds: market-led and government-led. Market dominance refers to the purchase of ecological services by beneficiaries from providers through price negotiation. Government-led means that the government, as a third party agency, negotiates prices with ecological service providers on behalf of ecological service providers. Scherr believes that the government as the main body to implement 
ecological compensation in the world is still the main mode of compensation [3].At present, there is no clear ownership of property rights in China's watershed ecological environment, and the pollutant emission property rights trading system is still in its initial stage, which will inevitably lead to the phenomenon of "vacant property rights subject" in the process of watershed ecological management, and the market fails to play its role, so that "Pareto optimality" cannot be achieved. The mechanism of ecological compensation in China is not yet perfect, and the main body of ecological compensation is not clear, especially the division of ecological responsibility between central government and local governmen, which leads to the water environment protection in the river basin into a dilemma.

\section{BASIC HYPOTHESIS AND MODEL CONSTRUCTION}

\subsection{Basic assumptions and parameter setting}

In this paper, the stakeholders of watershed ecological compensation are divided into the upstream, downstream and central governments, among which the central government and the downstream government are the main body of ecological compensation, while the upstream government is the recipient. As the coordinator and arbiter of ecological compensation, the central government's decision-making goal is to maximize the overall benefits of the basin and realize the sustainable development of the ecosystem of the basin. The decision-making goal of the upstream and downstream governments is to maximize their own interests within the administrative region. Therefore, this paper assumes that the upstream government and the downstream government in the basin act as the game parties, and the upstream government can choose whether to control the water pollution in the basin, so that the water quality in the upstream basin can be improved or not. Considering that the downstream government enjoys the positive external spillover benefits from the upstream government's water pollution control actions, the downstream government can choose to make ecological compensation to the upstream government, or choose no compensation strategy because of the possibility of "free ride". However, the (governance, compensation) strategy is the optimal strategy that the society expects to achieve, and the central government, as the coordinator, promotes the realization of this strategy combination through various regulatory means.

Based on the above assumptions, the following variables are defined:

$B_{1}$-- The inherent benefits of the upstream government's choice not to govern

$\mathrm{RB}_{1}$-- Political benefits obtained by the upstream government when it chooses governance strategies

$\mathrm{RB}_{2}$-- the economic benefits obtained by the upstream government under the governance strategy chosen

$\mathrm{RB}_{3}$-- Social benefits obtained under the governance strategy chosen by the upstream government

C -- the opportunity cost of direct costs and indirect losses incurred under the governance strategy chosen by the upstream government

$\mathrm{k}$-- Ecological compensation fees paid by the downstream government to the upstream government

$b_{1}$-- the benefit of the downstream government if the upstream government chooses not to govern

$\mathrm{Rb}_{1}$-- positive external spillover benefits obtained by the downstream government under the governance strategy chosen by the upstream government

$\mathrm{Rb}_{2}$-- the political benefits of the downstream government's choice of compensation strategy

$\mathrm{Rb}_{3}$-- Social benefits obtained by the downstream government's choice of compensation strategy

$\mathrm{x}$-- Probability of the upstream government to choose governance strategy $(0 \leq x \leq 1)$

y -- Probability of the downstream government to choose the compensation strategy $(0 \leq \mathrm{y} \leq 1)$

\subsection{Game model construction}

Based on the above assumptions and variable settings, the revenue functions of the upstream and downstream governments under different strategies can be obtained. In this regard, the following game model is established:

Table 1 Revenue matrix of dynamic evolutionary game model of upstream and downstream governments

\begin{tabular}{|c|c|c|c|}
\hline \multicolumn{4}{|c|}{ Upstream government } \\
\hline & & Governance $(\mathrm{x})$ & No governance $(1-\mathrm{x})$ \\
\hline & $\begin{array}{l}\text { Compensati } \\
\text { on }(y)\end{array}$ & $\begin{array}{c}\left(\mathrm{b}_{1}+\mathrm{Rb}_{1}+\mathrm{Rb}_{2}+\mathrm{Rb}_{3}-\mathrm{k}\right. \\
\left.\mathrm{B}_{1}+\mathrm{RB}_{1}+\mathrm{RB}_{2}+\mathrm{RB}_{3}+\mathrm{k}-\mathrm{C}\right)\end{array}$ & $\left(\mathrm{b}_{1}+\mathrm{Rb}_{2}+\mathrm{Rb}_{3}-\mathrm{k}, \mathrm{B}_{1}+\mathrm{k}\right)$ \\
\hline government & $\begin{array}{c}\text { No } \\
\text { compensati } \\
\text { on }(1-y)\end{array}$ & $\begin{array}{c}\left(\mathrm{b}_{1}+\mathrm{Rb}_{1}\right. \\
\left.\mathrm{B}_{1}+\mathrm{RB}_{1}+\mathrm{RB}_{2}+\mathrm{RB}_{3}-\mathrm{C}\right)\end{array}$ & $\left(b_{1}, B_{1}\right)$ \\
\hline
\end{tabular}




\section{DYNAMIC EVOLUTIONARY GAME ANALYSIS}

From Table 1, it can be obtained that in the dynamic evolutionary game model, the expected revenue U1 and $\mathrm{U} 2$ of the upstream and upper governments respectively under the strategy of "governance" and "non-governance", and the average expected revenue $\overline{\mathrm{U}} 1$ are:

$$
\begin{aligned}
& U_{1}=y\left(B_{1}+R B_{1}+R B_{2}+R B_{3}+k-C\right) \\
& +(1-y)\left(B_{1}+R B_{1}+R B_{2}+R B_{3}-C\right) \\
& U_{2}=y\left(B_{1}+k\right)+(1-y) B_{1} \\
& \bar{U}_{1}=x U_{1}+(1-x) U_{2} \\
& =x\left(U_{1}-U_{2}\right)+U_{2}
\end{aligned}
$$

Similarly, it can be obtained that the expected revenue $\mathrm{U} 3$ and $\mathrm{U} 4$, and the average expected revenue $\overline{\mathrm{U}} 2$ in the middle and lower reaches of the model when the governments choose "compensation" and "no compensation" strategies respectively are:

$$
\begin{aligned}
& U_{3}=x\left(b_{1}+R b_{1}+R b_{2}+R b_{3}-k\right) \\
& +(1-x)\left(b_{1}+R b_{2}+R b_{3}-k\right) \\
& U_{4}=x\left(b_{1}+R b 1\right)+(1-x) b_{1} \\
& \bar{U}_{2}=y U_{3}+(1-y) U_{4} \\
& =y\left(U_{3}-U_{4}\right)+U_{4}
\end{aligned}
$$

According to Equations (1) -- (3), (4) -- (6), the replicating dynamic equations $\mathrm{F}(\mathrm{x})$ and $\mathrm{F}(\mathrm{y})$ under the "governance" strategy of the upstream government and the "compensation" strategy of the downstream government can be respectively written:

$$
\begin{aligned}
& F(x)=\frac{d x}{d t}=x\left(U_{1}-\bar{U}_{1}\right) \\
& =x\left[U_{1}-x\left(U_{1}-U_{2}\right)-U_{2}\right] \\
& =x(1-x)\left(U_{1}-U_{2}\right) \\
& =x(1-x)(R B 1+R B 2+R B 3-C) \\
& F(y)=\frac{d y}{d t}=y\left(U_{3}-\bar{U}_{2}\right) \\
& =y\left[U_{3}-y\left(U_{3}-U_{4}\right)-U_{4}\right] \\
& =y(1-y)\left(U_{3}-U_{4}\right) \\
& =y(1-y)\left(R b_{2}+R b_{3}-k\right)
\end{aligned}
$$

According to the replicated dynamic equations (7) and (8), the stability analysis is carried out for the upstream government, the downstream government and the whole game system.

\subsection{Upstream government evolution path and stability strategy}

When $\mathrm{Rb} 1+\mathrm{Rb} 2+\mathrm{Rb} 3-\mathrm{c}=0, \mathrm{~F}(\mathrm{x})$ is equal to 0 . For all $\mathrm{x}$, it is a stable strategy of the upstream government, which does not meet the optimal strategy expected by the society.

According to the characteristics of the evolutionary stable strategy game, if a particular strategy is evolution of evolutionary stable strategy of the system, and then the strategy besides itself must be a stable state, must also have such properties: if some game due to accidental error strategy deviation from the evolutionary stable strategy, replicated dynamic still can make the strategy to reply to the evolutionary stable strategy. In mathematics, this is equivalent to requiring that the derivative of the replicated dynamic equation in which the evolutionarily stable strategy resides must be less than 0 .

When $\mathrm{RB} 1+\mathrm{RB} 2+\mathrm{RB} 3-\mathrm{C}>0$, if $\mathrm{F}(\mathrm{x})=0$, we can get $\mathrm{x}=0$ or $\mathrm{x}=1$. Since $\mathrm{F}^{\prime}(0)>0$ and $\mathrm{F}^{\prime}(1)<0, \mathrm{x}=1$ is the evolutionary stable state with the government above. The upstream government gradually shifts from "non-governance" strategy to "governance" strategy, and "governance" strategy becomes the evolutionary stable strategy of the upstream government.

When $\mathrm{RB} 1+\mathrm{RB} 2+\mathrm{RB} 3-\mathrm{C}<0$, if $\mathrm{F}(\mathrm{x})=0$, we can get $x=0$ or $x=1$. Since $F^{\prime}(0)<0$ and $F^{\prime}(1)>0, x=0$ is the evolutionary stable state of the upper government, and the upper government gradually shifts from "governance" strategy to "non-governance" strategy, and the "non-governance" strategy becomes the evolutionary stable strategy of the upper government.

To sum up, when $\mathrm{RB} 1+\mathrm{RB} 2+\mathrm{RB} 3-\mathrm{C}>0$, the "governance" strategy becomes the evolutionary stability strategy of the upstream government, and when $\mathrm{RB} 1+\mathrm{RB} 2+\mathrm{RB} 3-\mathrm{C}<0$, the "non-governance" strategy becomes the evolutionary stability strategy of the upstream government. However, in real life, it is difficult to meet the condition of $\mathrm{RB} 1+\mathrm{RB} 2+\mathrm{RB} 3-\mathrm{C}<0$, and the input cost of the upstream government in water pollution treatment is often greater than the benefits, that is, "C>RB1+RB2+RB3". Therefore, the "non-governance" strategy becomes the evolutionary and stable strategy of the upstream government, and the optimal strategy expected by the society is difficult to achieve.

\subsection{Downstream government evolution path and stability strategy}

Similarly, $F^{\prime}(y)=(1-2 y)(R b 2+R b 3-k)$. In real life, the ecological compensation paid by the downstream government is often greater than the sum of the political and social benefits obtained by the downstream government, that is, Rb2+Rb3-k<0, $F^{\prime}(0)<0, F^{\prime}(1)>0$, 
so $\mathrm{y}=0$ is the evolutionary stable state of the downstream government. Therefore, the downstream government gradually moves from "compensation" strategy to "no compensation" strategy. At this time, the optimal strategy that the society expects to achieve cannot be realized.

\subsection{Stability analysis of dynamic evolutionary game model of upstream and downstream governments}

Replication dynamic system is composed of upper and lower government replication dynamic equations to form the evolutionary game model. The equilibrium point analysis of the Jacobian matrix of the system is carried out to verify the stable state of the system, and then the strategy selection and evolution state of the upstream and downstream governments are analyzed. The following Jacobian matrix is constituted by (7) and (8) :

$$
J=\left(\begin{array}{ll}
(1-2 x)\left(R B_{1}+R B_{2}+R B_{3}-C\right), & 0 \\
0 \quad,(1-2 y)\left(R b_{2}+R b_{3}-k\right)
\end{array}\right)
$$

$|J|=(1-2 x)\left(R B_{1}+R B_{2}+R B_{3}-C\right)(1-2 y)\left(R b_{2}+R b_{3}-k\right)$

$$
\begin{aligned}
& \operatorname{tr}(J)=(1-2 x)\left(R B_{1}+R B_{2}+R B_{3}-C\right) \\
& +(1-2 y)\left(R b_{2}+R b_{3}-k\right)
\end{aligned}
$$

Now, it is assumed that the (governance, compensation) strategy is the evolutionary stability strategy of the system. At this time, $(x=1, y=1)$ is the stable equilibrium point of the evolutionary game model, and the two conditions of $\operatorname{Det}(\mathrm{J})>0$ and $\operatorname{Tr}(\mathrm{J})<0$ are satisfied at the same time. Substract $(x=1, y=1)$ into Equations (10) and (11) to obtain the following equation:

$$
\left\{\begin{array}{c}
\left(R B_{1}+R B_{2}+R B_{3}-C\right)+\left(R b_{2}+R b_{3}-k\right)>0 \\
\left(R B_{1}+R B_{2}+R B_{3}-C\right)\left(R b_{2}+R b_{3}-k\right)>0
\end{array}\right.
$$

$" \operatorname{tr}(\mathrm{J})=(\mathrm{C}-\mathrm{RB} 1-\mathrm{RB} 2-\mathrm{RB} 3) \quad-(\mathrm{Rb} 2+\mathrm{Rb} 3-\mathrm{k})<0 " \quad$ is in contradiction with"RB1+RB2+RB3-C $<0$ ", which is derived by $" R b 2+R b 3-k<0 "$ and $" \operatorname{det}(J)>0$ ", so the hypothesis is not valid." $(\mathrm{x}=1, \mathrm{y}=1)$ " is not the stable equilibrium point of the evolutionary game model, that is, the upstream government chooses the governance strategy, and the downstream government makes ecological compensation for it cannot evolve the evolutionary stability strategy of the upstream government and the downstream government. This conclusion is consistent with the previous evolutionary path analysis conclusion of the upstream government and the downstream government.

\section{CONCLUSION}

In this paper, the dynamic evolutionary game analysis method is used to study the decision-making behavior among the ecological compensation benefit main body of a river basin. We can make the following conclusions: first, in the process of river basin ecological compensation, if only the government and the downstream government involved, so in order to pursue the maximization of self-interest, upstream of the government will take "governance" strategy, downstream of the government to take "no compensation strategy, which fall into prisoner's dilemma. At this time, the upstream government has no initiative to provide ecological services, and the downstream government has no incentive to pay for ecological compensation. The ecological resources of the river basin are gradually exhausted and the ecosystem is destroyed. In a word, the "Pareto Optimality" desired by society cannot be achieved only by the independent negotiation between the upstream government and the downstream government. Second, governments of the upper and lower reaches of the river basin should establish binding incentive mechanisms for ecological compensation .By introducing the central government to establish a reasonable and effective incentive and constraint mechanism, the upstream and downstream governments can sign a binding ecological compensation agreement to clarify the subject and object of ecological compensation, so as to realize the optimal overall benefits of the basin. Third, the practice of watershed ecological compensation should be combined with the local reality, and the appropriate watershed ecological compensation mode should be selected according to local conditions. In addition, due to the lack of ecological compensation legislation in China, the local practice of watershed ecological compensation generally falls into the dilemma of lack of legal basis. It is necessary to improve the laws and regulations of ecological compensation, ensure the legitimacy of the ecological compensation mechanism, ensure the sustainability of the ecological compensation policy, and promote the ecological compensation in the river basin into the track of legality and regularization [4].

\section{REFERENCES}

[1] Kosoy, N., Tuna, M., Muradian, R.(2007)Payments for environmental services in watersheds: Insights from a comparative study of three cases in Central America. J.Ecological Economics,61:446-455.

[2] Vatn, A. (2010) An institutional analysis of payments for environmental services. J.Ecological Economics, 69: 1245-1252.

[3] Milne, S., Adams, B. (2012) Market Masquerades: Uncovering the Politics of Community-level 
Payments for Environmental Services in Cambodia.J. Development and Change,43:133158.

[4] Zhou, H.W., Peng Y.M. (2020) Research on the ecological compensation mechanism of water flow in the Taihu Lake Basin.J. Yangtze River, 51: 8185. 